\title{
A Comparison of Monte Carlo Simulation and Discounted Cash Flow Investment Appraisal Techniques Using an Office Building in Akure, Nigeria
}

\author{
Akinbogun S. P. ${ }^{1, *}$, Binuyo O. P. ${ }^{1}$ and Akinbogun O. T. ${ }^{1}$ \\ ${ }^{1}$ Department of Estate Management, Federal University of Technology, Akure, Nigeria \\ Corresponding Author: *akinbogunpelumi@yahoo.com | spakinbogun@futa.edu.ng
}

\begin{abstract}
Every rational investor aimed to secure an optimum return from an investment at certain level of risk. However, the factors that affect the realization of the expected return are not known with certainty. Therefore, the reliability of a single point estimate for investment decision is debatable particularly when the likelihood of realizing the expected return is crucial to the investor. This study aimed at examining a better method of analysing the uncertainty in property investment rather than the use of the single point estimate formula. We collected a set of historic data from a multi-tenanted office complex in Akure to carry out the investment analysis using Monte Carlo simulation and Discounted Cash Flow Technique. The results from the study were compared and revealed that the single point estimate accounted for a huge level of risk as probability of realizing the expected return is unknown. The Monte Carlo simulation offers a more robust opportunity for a measured investment decisions by providing a probability of realizing different level of the expected returns. The study concludes that it is difficult to make a smart investment decision on a single point estimate. It therefore recommends the use of Monte Carlo simulation for property investment analysis for a more realistic return.
\end{abstract}

Keywords: Monte Carlo, Nigeria, Simulation, Single-point estimate, Probabilistic

\subsection{Introduction}

Investment generally denotes the giving up of capital sum in expectation of future return or stream of income (Martin, 2010). A rational investor therefore considers the total cost of the investment with the return, minding the time, size, value and the flow of the expected return from the investment (Babawale, 2007). Real estate investment analysis often involves the use of the traditional deterministic approach. This approach does not take cognizance of the uncertainties surrounding the cash flows (Hoesli, et al., 2005). It only assumes a theoretical certainty in estimating the investment analysis variables. In this, investment analysts usually adopt the single point estimation for the analysis (Kelliher and Mahoney, 2000; French and Gabrielli, 2004). The exact state of each of these variables in the future is often uncertain at the time the investment decision is made, and a future change in any of these variables could culminate in a misleading analysis.

There is therefore a need for proper account for future uncertainty in investment analysis, real estate investment inclusive. An accurate management of the effect of uncertainty in real estate investment enhances the credibility and reputation of the analyst and the utility of the analysis and method/technique (French and Gabrielli, 2004). Therefore, it is necessary for investment analysts to ensure that the method used for real estate investment analysis gives allowance for future uncertainties that could arise in the projected investment variables. This could be done by generating a stochastic process for the variables which the deterministic approach is incapable, hence a need for a probabilistic approach (Balogh et al., 2013).

Monte Carlo simulation is a form of probabilistic investment analysis which gives an opportunity for stochastic process for the investment variables unlike the close-form formulas of the single point estimates. This is able to give an opportunity for developing large scenarios to accommodate several 
future possibilities (Baroni et al., 2006). Uncertainties in real estate portfolio are most times beyond the control of the investor and there is rationally an urge into searching for probable effects of these uncertainties in order to take viable decision on the investment. Both cash inflows and cash outflows are parts of the elements that constitute risk and uncertainty to the investors and therefore require adequate consideration in the investment analysis (Suhonen, 2014).

Monte Carlo simulation generates several scenarios that could possibly arise in the future around the single point estimation. It starts from the extreme worse case scenarios to the extreme good situation, and for each of these scenarios, the chosen single point investment analysis model is applied (Baroni et al 2006). The results from the Monte Carlo simulation analysis could then be statistically analysed to have a basis for the comparison with the single point estimation and then used to give advice to the investor on what could probably happen in the future and the chances of occurrence of the implications of changes in the various investment variables.

\subsection{Single-point estimate approach of real estate investment analysis}

The single point estimate considers the determination of what is possible to be the estimates of the variable input and appraised the investment on this, using closed-form formulas (Dupuy, 2003). One of the popular methods of using the single point estimate for real estate investment analysis is the Discounted Cash Flow (DCF) approach (Suhonen, 2014). This refers to an income valuation, where there is an application of a particular discount rate to investment cash flow for a given number of years, discounted to the present value (Damodaran, 2002). The DCF works on the premise of calculating the present value of expected future income for each year of the cash flow period. It also gives consideration for the residual value at the end of the holding period (Fetibegovic and Nilsson, 2011). The DCF does not give account to variability of the parameters due to risk and uncertainty. It only runs with the estimated variable and computes the appraisal singly (Dupuy, 2003; Suhonen, 2014). According to Kelliher and Mahoney (2000), the DCF technique makes use of the future cash flow, timing of the future cash flows, the discount rate. The Discounted Cash Flow is defined as;

$$
\mathrm{PV}=\sum \frac{\mathrm{C}_{\mathrm{t}}}{(1+r)^{t}}-I_{0}
$$

where $\mathrm{PV}=$ present $\left(\right.$ market) value; $\mathrm{C}_{\mathrm{t}}=$ forecasted incremental cash flow after corporate taxes - strictly speaking the mean of the distribution of possible $C_{\mathrm{t}}$ values, $\mathrm{t}=$ project life $(\mathrm{Ct}$ includes any salvage value) and $r=$ the opportunity cost of capital defined as the equilibrium expected rate of return on securities equivalent in risk in the project being valued.

Suhonen (2014) compared the Monte Carlo simulation with the DCF in supporting retail real estate investment decision. The results of the study showed that the traditional DCF is an investment appraisal method which gives only a single point valuation. Babawale (2007) examined four conventional single point estimates techniques; the payback period, the risk adjusted rate, discounted cash flow and sensitivity analysis and explained that these traditional valuation methods suffer from numerous limitations and criticisms, but, in particular, they all suffer at least from the same inherent limitations: they do not appropriately take the risk into account and they are highly sensitive to changes in parameters that constitute risk (Amedee-Manesme, et al., 2011). The use of Discounted Cash Flow (DCF) in real estate investment analysis has been discussed in several literatures; their applications, advantages and shortcomings, especially in not being able to account for uncertainty (Hoesli et al, 2006; Ojo, 2006; Babawale, 2007 and Amedee-Manesme et al, 2011). However, most of these literatures that examined the shortcomings of the single point estimate were mostly foreign to Nigeria. The results of Babawale (2007) which is Nigerian also needs to be updated and examined on another property investment opportunity, and in this study, the office building is considered.

\subsection{Monte Carlo Simulation of real estate investment appraisal}

Uncertainty is a common phenomenon in real estate investment. It is not absolutely certain that the expected future income from real estate investment would be as realized. Uncertainty refers to anything that is not known about the outcome of a venture as at the time of investment decision. The uncertainty surrounding the use of the single point estimate in the traditional DCF investment analysis process 
comes from possible incorrect estimation of the input figures in the analysis. It could be possible to have a prediction of the probable values, but the possibility of variation is unavoidable (French and Gabrielli, 2004). Therefore, investment analysts develop models which could account for the uncertainties that surround the variables used in the investment analysis. One of these methods is the use of Monte Carlo simulation technique, which assigns probabilities to the input variables of the DCF model (Adair, 1996).

Monte Carlo Simulation has been used in finance to simulate iterations for the prices of derivatives and to predict future prices of stock (Hoesli et al., 2006). In real estate investment analysis, Pyhrr (1973) created a simulation model for the measurement of the risk associated with the investment. The study compared the use of the traditional DCF with Simulation analysis of the investment. Unlike the DCF method, Pyhrr (1973) found that the Simulation was able to accommodate the risk associated with the investment. Much of the later studies on the topic are based on this initial research of Pyhrr (1973).

Hoesli et al (2006) used Monte Carlo simulation to predict property values with the use of adjusted present value method and discovered that central values of the simulations are in most cases slightly less than the hedonic values. The confidence intervals are found to be most sensitive to the long-term equilibrium interest rate being used and to the expected growth rate of the terminal value. Most importantly, Hoesli et al (2006) also found that the use of Monte Carlo simulation has been found to be a useful tool for improving long-term investment decision making.

Amedee-Manesme et al, (2011) also combined the Monte-Carlo simulations and options for the management of risk of real estate portfolios. The study used Monte Carlo approach to simulate the probabilities surrounding the market prices and rental values. It revealed that the Monte Carlo simulation could distribute the probability of the cash flows over the period of the investment. The findings of Amedee-Manesme et al (2011) is in consonance with Baroni et al (2005) where Monte Carlo Simulation was used to simulate the rental value and the price of the investment. Baroni et al (2005) was also able to simulate the terminal value rather than the usual traditional method which is dependent on hazardous infinite growth rate.

Jayaraman's (2013) review of Monte Carlo methods in real estate investment analysis explained that the technique was able to account for the uncertainty introduced into the analysis by the different parameters in consideration. The study found that the technique of Monte Carlo simulation could be adapted to the various traditional models of real estate investment analysis like the Discounted Cash Flow (DCF) and the Adjusted Present Value (APV) to properly account for uncertainties in real estate investment analysis. The study also revealed that the uncertainty is modeled in the Monte Carlo approach as a probabilistic differential equation which is simulated through the technique. Keith (2014) incorporated uncertainty into real estate investment analysis. The study made use of the probabilistic technique of Monte Carlo simulation to incorporate the uncertainties and the various options in real estate investment decisions. It was found from the work that the Monte Carlo simulation was able to provide different results rather than the single results from the deterministic models. This was found to be able to give the real estate investment analysts different angles of addressing real estate valuations problems.

In Nigeria, Babawale (2007) also worked on risk analysis in property investment using Monte Carlo Simulation Technique. The study carried out the analysis of a 55-room hotel development using the conventional method and then compared with the results from the Monte Carlo simulation technique. The study discovered that the Monte Carlo simulation technique offers possibilities of overcoming some of the weaknesses of the conventional methods as highlighted in the previous researches on the subject matter.

Observation shows that the application of Monte Carlo simulation in real estate investment analysis is fairly limited due to its demand for mathematical and statistical understanding (Hoesli et al, 2006). This has limited its application in real estate investment analysis in the developing nations of the world, Nigeria inclusive. However, the availability of different statistical software packages and technologies gives a good platform for carrying out Monte Carlo Simulation and in this study, the use of Microsoft Excel, which Nigerian investment analysts are more familiar with, is adopted for the simulation analysis. 
This paper therefore applies the Monte Carlo simulation technique for real estate investment analysis using Micosoft Excel package which is more readily available to Nigerian real estate analysts. This is done with a view to validating the outcome of previous similar researches which were mostly from the developed countries of the world in a Nigeria city and with a particular reference to an office building unlike Babawale (2007) which was also in Nigeria but considered a hotel building at Lagos. This paper therefore aims at using the Monte Carlo simulation technique to analyze an office complex investment in Akure and comparing the results with a deterministic approach. This is done with a view to advising local real estate investment analysts on the best method to employ when dealing with the uncertainties.

\subsection{Materials and Methods}

\subsection{Research design}

This study adopted a purposive technique to collect data from some professionals in the built environment. These data are non-probabilistic in nature and are gotten from the respondents based on the probability of pessimism, optimism and the most possible. These data collected are then analyzed using both the Discounted Cash Flow (DCF) and the Monte Carlo Simulation.

\subsection{Target population}

The professionals in the built industry, especially the Estate Surveyors and Valuers, the Quantity Surveyors, the real estate developers were administered both close and open-ended questionnaire.

\subsection{Study area and Case study property}

Akure is the capital and the most populated city in Ondo State, South west Nigeria, characterised by the presence of notable commercial, financial and educational institutions being the state capital and the main administrative center of the state. The property market, even though nascent, is growing at a very high rate due to an increasing rate of immigration.

The case study property considered in this paper is the Nigerian Agricultural Cooperation and Rural Development Bank (NACRDB) building, an office complex, in Alagbaka commercial area, of Akure and is occupied by corporate offices. The property is a two-storey building, situated in a Central Business District (CBD) of the city, which makes it a good location for office building investment. It is one of the major purpose-built office properties in the location, where the historical records needed for this analysis could be easily gotten and used as a good sample for such investment in Alagbaka, Akure.

\subsection{The data for the analysis}

The data collected from the professionals was on the basis of the maximum, minimum and the best estimate values were derived from the average of the maximum and minimum values (see Table 1). For the simulation analysis, 1500 iterations were generated on Microsoft excel package.

Table 1: Table showing the data

\begin{tabular}{lll}
\hline Data required & Source & Number of Professionals considered \\
\hline The unit cost of construction & Quantity surveying firms & Ten (10) \\
\hline Rent per meter square & $\begin{array}{l}\text { Estate Surveyors and Valuers (Both the firm in } \\
\text { charge of the management of the building and the } \\
\text { firms occupying the building) }\end{array}$ & $\begin{array}{l}\text { Six (1): } \\
\text { The managing firm and Five other estate } \\
\text { surveying firms located on the building }\end{array}$ \\
\hline $\begin{array}{l}\text { Unit cost of repair and } \\
\text { maintenance }\end{array}$ & $\begin{array}{l}\text { Quantity surveyor and the managing Estate } \\
\text { surveyors and Valuers }\end{array}$ & $\begin{array}{l}\text { Ten (10) Quantity Surveying firms and } \\
\text { the managing Estate surveying firm }\end{array}$ \\
\hline Yield on the investment & Estate Surveyors and Valuers & Six (6) estate surveying firms \\
\hline Year of investment & Estate Surveyors and Valuers & Six estate surveying firms \\
\hline Year of review & Estate Surveyors and Valuers & Six estate surveying firms \\
\hline
\end{tabular}




\subsection{Methods of Data Analysis}

The descriptive statistics analysis was employed in this study. The descriptive statistics tools are; Mean, Standard deviation, Skewness and Kurtosis in analyzing the simulated results. The analysis of the single point estimate viability was done using the Discounted Cash Flow approach; DCF is defined as follows:

$P V=\sum \frac{\mathrm{C}_{\mathrm{t}}}{(1+r)^{t}} I_{0}$,

where $\mathrm{PV}=$ present $\left(\right.$ market) value; $\mathrm{C}_{\mathrm{t}}=$ forecasted incremental cash flow $\mathrm{t}=$ project life; $\mathrm{r}=$ the opportunity cost of capital defined as the equilibrium expected rate of return on securities equivalent in risk in the project being valued. Io=initial capital outlay. NPV equals PV less the cash outlay required (initial investment).

\subsubsection{Monte Carlo simulation model}

Monte Carlo simulation model is given by:

$\operatorname{Pr}\left[\frac{1}{N} \sum_{N} \varepsilon-\mu<3 \sigma / \sqrt{N}\right] \approx 99.8 \%$

where $\mathrm{N}$ is the number of iterations, $\varepsilon$ is the error term and is denoted by $3 \sigma / \sqrt{N}, \sigma$ is the standard deviation (Wayne, 2004). To determine the required sample for simulation, the follwing model was used;

$\mathrm{N}=\left(\begin{array}{c}3 \times 0 / \\ \varepsilon\end{array}\right)^{2}$,

where $\mathrm{N}$ is the number of iterations, $\sigma$ is the standard deviation, $\varepsilon$ is the total error. In Microsoft Excel, $\sigma=$ STVDEVP(MINIMUM:MAXIMUM, while, $\varepsilon=$ AVERAGE(MINIMUM:MAXIMUM)/1500.

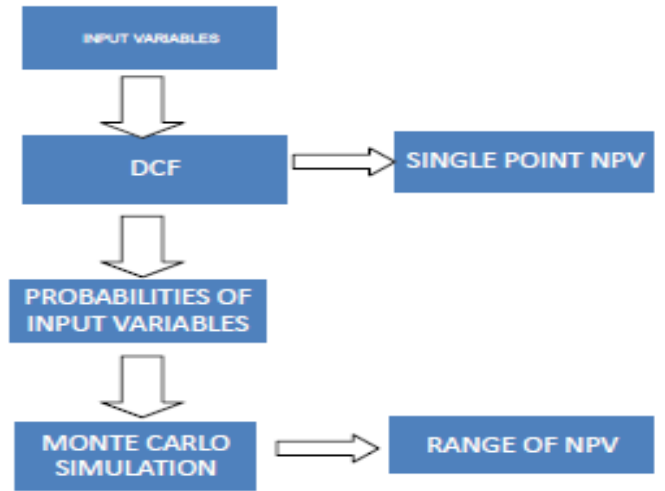

Figure 1: Flow chart of the Monte Carlo Simulation process

\subsection{Results and Discussion}

The minimum and maximum values were gotten from the responses of the respondents to the questionnaire as shown in Table 2. The rent per square meter in the building is within the range of $\mathrm{N}$ 5,000 and $\mathrm{N}$ 8,000 per annum depending on the floor. The cost of repair and maintenance and other ancillary cost during tenancy is in the range of $\mathrm{N} 83.333$ and $\mathrm{N} 111.111$. The cost of construction per meter square is in the range of $N 65,000$ and $N 70,000$. The average of the responses of the respondents on each of these data was used as the most probable estimate. The data obtained from the estate surveying and valuation firms indicate that rent review of such property is done on $10 \%$ upward review (inflation rate induced), which also reflects in the review of the cost of repair and maintenance. The discount rate is in the range of 5\% - 15\% as gotten from the Estate Surveying and Valuation firms and empirically substantiated in Udoekanem et al, (2014). 
Table 2: The Data for the Investment Analysis

\begin{tabular}{|c|c|c|c|c|c|}
\hline $\mathbf{S} / \mathbf{N}$ & Data & Source of data & $\begin{array}{l}\text { Most possible } \\
\text { maximum value }\end{array}$ & $\begin{array}{l}\text { Most possible } \\
\text { minimum value }\end{array}$ & $\begin{array}{r}\text { Most probable } \\
\text { (best estimates) }\end{array}$ \\
\hline 1. & Rent per meter square & $\begin{array}{l}\text { Estate surveyors and } \\
\text { valuers }\end{array}$ & $\mathrm{N} 8,000$ & A 5,000 & $\mathrm{~A} 6,500$ \\
\hline 2. & $\begin{array}{l}\text { Cost of construction per square } \\
\text { meter }\end{array}$ & Quantity surveyors & A 70,000 & A 65,000 & N 66,000 \\
\hline 3. & $\begin{array}{l}\text { Cost of maintenance and repair } \\
\text { per square meter }\end{array}$ & $\begin{array}{l}\text { Quantity surveyor and } \\
\text { estate surveyors and } \\
\text { valuers }\end{array}$ & A 111.111 & A 83.333 & N 90 \\
\hline 4. & $\begin{array}{l}\text { Discount rate on commercial } \\
\text { property }\end{array}$ & $\begin{array}{l}\text { Estate Surveyors and } \\
\text { valuers }\end{array}$ & $15 \%$ & $5 \%$ & $12.5 \%$ \\
\hline 5. & year of the investment & $\begin{array}{l}\text { Real estate investors; } \\
\text { estate surveyors and } \\
\text { valuers }\end{array}$ & & & 20 YEARS \\
\hline 6. & $\begin{array}{l}\text { Growth rate every } 4 \text { years } \\
\text { (inflation rate induced). } \\
\text { applicable to the repair and } \\
\text { maintenance cost }\end{array}$ & $\begin{array}{l}\text { Estate Surveyors and } \\
\text { Valuers }\end{array}$ & $11 \%$ & $9 \%$ & $10 \%$ \\
\hline 7. & Year of review & & & & Every 4 Years \\
\hline 8. & $\begin{array}{l}\text { Inflation rate as at the time of } \\
\text { analysis }\end{array}$ & CBN publication & $11 \%$ & $9 \%$ & $10 \%$ \\
\hline
\end{tabular}

\subsection{Appraising the Investment Using DCF Single Point Estimate}

The terminal value of the investment was derived by directly capitalizing the cash inflow for the next year after the investment period has been exhausted, for the remaining 79 years permissible according to the Land Use Act, 1978.

The capitalization rate is given as:

$$
\frac{1-P V}{i} \text {, }
$$

where,

$$
\mathrm{PV}=\frac{1}{A}
$$

Cash inflow for the next year after the investment period has been exhausted $=10,323.369$. The capitalization rate/discount rate $=15 \%$. The calculation from equation (5) gives 6.6666. This is then multiplied by the expected cash inflow for the year after the investment period has been exhausted;

$6.6666 * 10,323.369=\$ 68,821.367$. Therefore, the terminal value is $=\$ 68,821.367$.

\begin{tabular}{|c|c|c|c|c|c|}
\hline Year & Rent/ $\mathbf{M}^{2}(\mathbf{N})$ & $\operatorname{Cost} / M^{2}(\mathbf{N})$ & Net $\operatorname{Rent} / \mathbf{M}^{2}(\mathrm{~N})$ & PV N1@12.5\% & DCF \\
\hline $1-2$ & 6500.00 & 90.000 & 6410.000 & 1.000000 & 6410.000 \\
\hline $3-4$ & 6500.00 & 90.000 & 6410.000 & 0.790123 & 5064.691 \\
\hline $5-6$ & 7150.00 & 99.000 & 7051.000 & 0.624295 & 4401.905 \\
\hline $7-8$ & 7150.00 & 99.000 & 7051.000 & 0.493270 & 3478.048 \\
\hline $9-10$ & 7865.00 & 108.900 & 7756.100 & 0.389744 & 3022.896 \\
\hline $11-12$ & 7865.00 & 108.900 & 7756.100 & 0.307946 & 2388.461 \\
\hline $13-14$ & 8651.50 & 119.790 & 8531.710 & 0.243315 & 2075.897 \\
\hline $15-16$ & 8651.50 & 119.790 & 8531.710 & 0.192249 & 1640.215 \\
\hline $17-18$ & 9516.65 & 131.769 & 9384.881 & 0.151901 & 1425.570 \\
\hline $19-20$ & 9516.65 & 131.769 & 9384.881 & 0.120020 & 1126.376 \\
\hline
\end{tabular}

Table 3: Table showing the single point estimate of the investment

On a single point estimate, the cost of construction per square meter is $\$ 66,000$, the terminal value at the end of 20 years, as calculated with the formula in equation (5) gives $\$ 68,821.367$. Therefore, the NPV on the single point estimate is calculated as follows; 
Using equation 2 and values of single point estimate from Table 3 , the sum of the DCF is $\$ 33,855.417$ (obtained from: $\mathrm{PV}=\sum \frac{C f}{(1+i)^{t}}+$ Terminal Value $-I_{0}=31034.06+68,821.367-66,000=\$ 33,855.417$ )

Therefore, from the single point estimate analysis, the investment is expected to be viable at $\$ 33,855.417$. This indicates that the investment is viable based on the rent per square meter.

In reality, the chance of occurrence and other possible outcomes are not included in this estimation, hence a need for more robust method of analysis.

\subsection{Appraising the Investment via Monte Carlo Simulation}

Monte Carlo Simulation was adopted, the model in equation 2 was applied to carry out the analysis in Microsoft Excel. This was run to simulate 1500 scenarios that could occur within the range of input values given. The descriptive statistics which validate the reliability of the simulation are presented in Table 4.

Table 4: Summary of simulation viability results

\begin{tabular}{ll}
\hline No. of iterations & 1500 \\
Mean & 17850.34 \\
Standard Deviation & 11414.23 \\
Skewness & 0.680 \\
Kurtosis & -0.574 \\
Minimum & 693.40 \\
Maximum & 49493.14 \\
\hline
\end{tabular}

From Table 4, the Skewness shows that the distribution of the data is more to the positive, right side at 0.680 while the -.574 value of the Kurtosis shows a relatively flattened top of the distribution of the data. The Skewness and Kurtosis still hold for the assumption of normality of the distribution of the Monte Carlo simulation results, as they are both not outside the range of -1.0 and +1.0 . The value of the mean of the results of the viability from the simulation is 17850.34 . This value is however higher than the highest possible viability of occurrence as shown in Table 2 . The minimum viability value is 693.40 while the highest possible viability value is $49,493.14$. This shows a huge variation in the viability of the investment that could occur if there is such change in the choice in the input variables by the analyst. The Standard Deviation Value of 11414.23 shows a high amount of viability variation possible from the mean value of the viability of the investment.

Most of the simulation output was reported in the $\$ 5001$ to $\$ 10000$ range followed by the $\$ 10001$ $\$ 15000$ range (See Table 5). The least return came in the \$45001 to \$50000 range, with 12 outcomes. The single point estimate gave a result of $\$ 33,855.417$ that falls within the range of $\$ 30001-\$ 35000$, with the probability of occurrence of 0.073 and the probability of not achieving at 0.832 . However, from the simulated results, the range of the most probable chance of occurrence is $\$ 5000$ to $\$ 10000$, which is lower than the prediction from the single point estimate, a confirmation that the single point estimate can be misleading; this result corroborates the findings from Babawale (2007).

The advantage of the Monte Carlo simulation over the single point estimate is in the ability to give a better understanding of the various possible outcomes from the investment, using the iterated possibilities (See Figure 2 and Figure 3). This provides a better understanding of investment decision using the various possible estimates. If a single point estimate has been used for investment decision making, based on the high level of income from the investment, which is not impossible, say, on the NPV of $\$ 5001$ to $\$ 50000$ range, the probability of achieving this is however very low at 0.008 while the probability of not achieving high at 0.927 , ditto all other higher NPV results. What is most probable is the result from the NPV of the range $\$ 5001$ to $\$ 10,000$ at 0.222 . The standard deviation of $\$ 11414.23$ shows the huge risk factor of $\$ 11414.23$ if the decision on investment is based on a single point estimate. 
Table 5: Results from the Simulation with the Frequency and Probability of their Achievement

\begin{tabular}{ccccccc}
\hline $\begin{array}{c}\text { NPV } \\
\text { Range(N) }\end{array}$ & Frequency & $\begin{array}{c}\text { Cumulative } \\
\text { frequency of } \\
\text { NPV }\end{array}$ & Percentage & $\begin{array}{c}\text { Probability } \\
\text { of achieving }\end{array}$ & $\begin{array}{c}\text { Cumulative } \\
\text { frequency of } \\
\text { probability of } \\
\text { achieving }\end{array}$ & $\begin{array}{c}\text { Probability } \\
\text { of not } \\
\text { achieving }\end{array}$ \\
\hline $0-5000$ & 141 & 141 & 9.4 & 0.094 & 0.094 & 0.906 \\
$5001-10000$ & 334 & 475 & 22.26 & 0.223 & 0.317 & 0.777 \\
$10001-15000$ & 252 & 727 & 16.8 & 0.168 & 0.485 & 0.832 \\
$15001-20000$ & 203 & 930 & 13.5 & 0.135 & 0.62 & 0.865 \\
$20001-25000$ & 179 & 1109 & 11.93 & 0.119 & 0.739 & 0.881 \\
$25001-30000$ & 130 & 1239 & 8.67 & 0.087 & 0.826 & 0.913 \\
$30001-35000$ & 110 & 1349 & 7.33 & 0.073 & 0.899 & 0.927 \\
$35001-40000$ & 93 & 1442 & 6.2 & 0.062 & 0.961 & 0.938 \\
$40001-45000$ & 46 & 1488 & 3.07 & 0.031 & 0.992 & 0.969 \\
$45001-50000$ & 12 & 1500 & 0.8 & 0.008 & 1 & 0.992 \\
TOTAL & 1500 & & 100 & 1 & & 9 \\
\hline
\end{tabular}

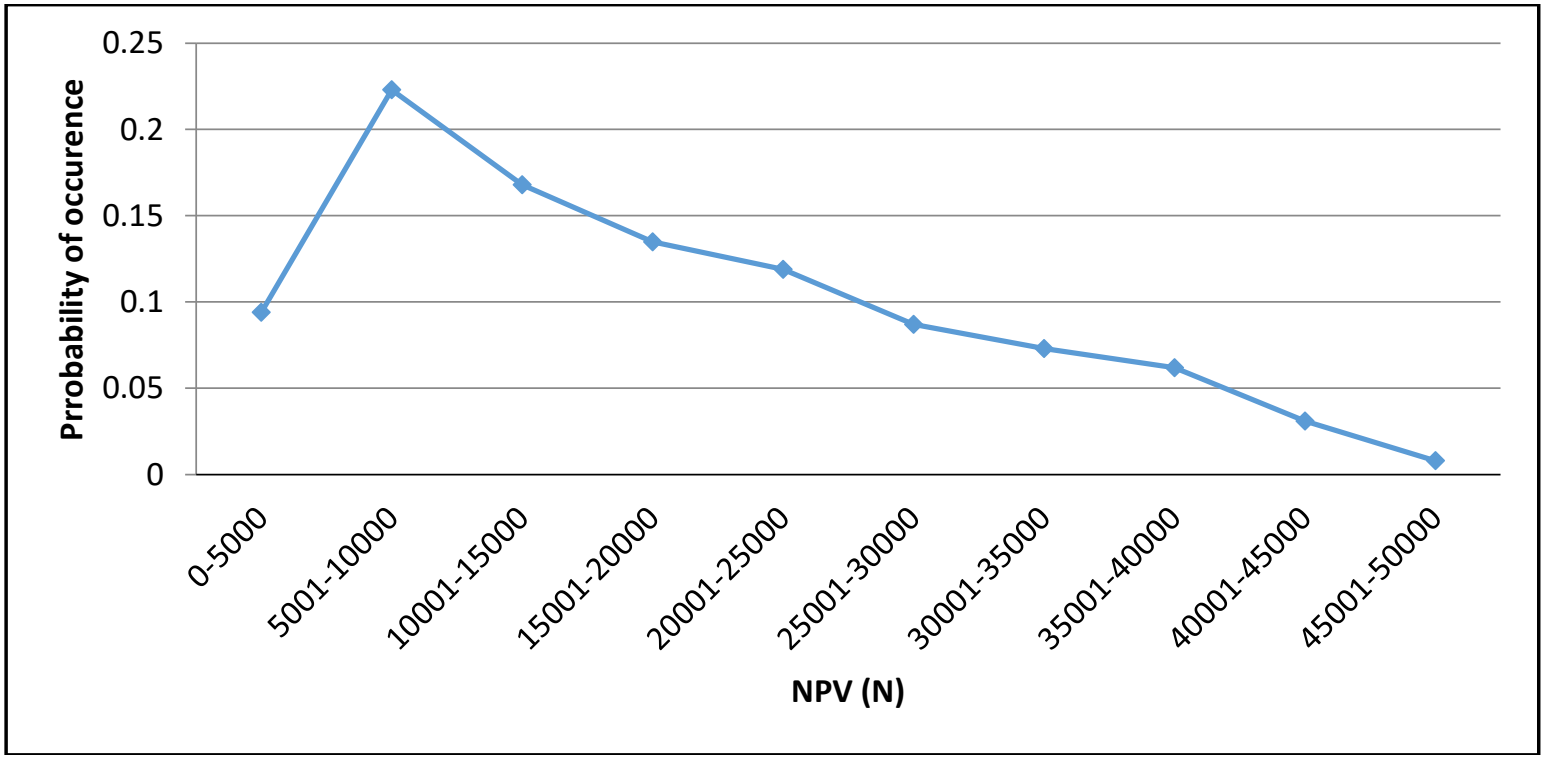

Figure 2: Estimated Returns and Corresponding Chances of Occurrences

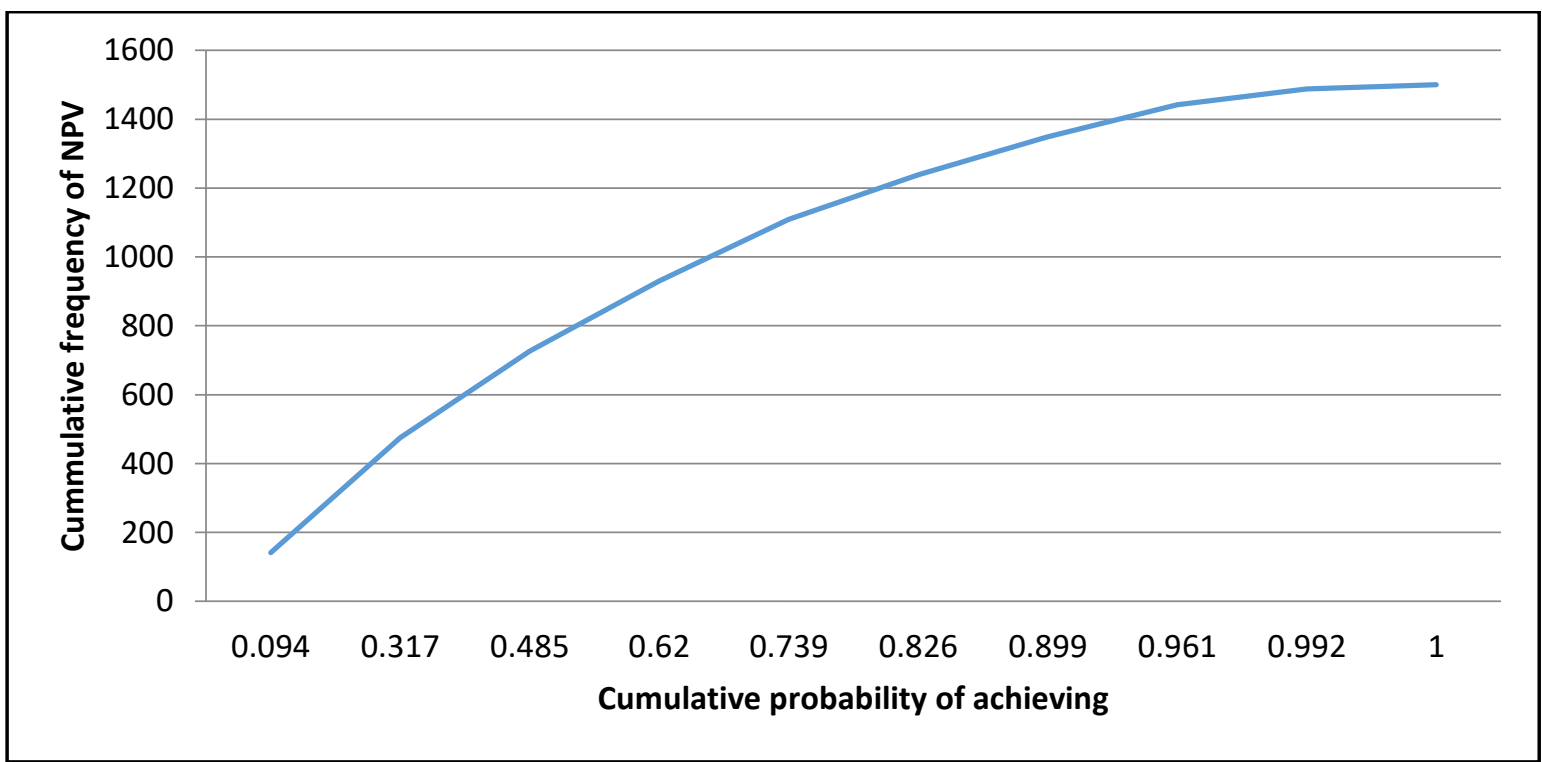

Figure 3: Graph of cumulative probability of achieving against the cumulative frequency of NPV 


\subsection{Conclusions}

This study evaluates and compares the DCF and Monte Carlo simulation in investment appraisal. It applies primary data collected from an office complex. Analysis of the results from the DCF produced a single point estimate of the investment whose certainty is unknown. Using the same data, the Monte Carlo simulation analysis generated a range of results with known possibilities of occurrence. This implies that the result from the single point estimate could be misleading as the probability of realizing the estimate is unknown. The Monte Carlo simulation offers robust results with known possibilities. This gives the investors the opportunities to compare the probable outcomes from the several iterations. Subject to the level of risk preferred, the simulation allows the investor to choose a desired level of return from the investment.

The results of the analysis of this study have shown that the use of single point estimate in office building investment analysis is not capable of properly explaining the inherent uncertainties. However, the use of Monte Carlo Simulation was not only able to identify the uncertainties but also presents the chances of occurrence of the various outcomes of the investment decision.

It is shown from this study that property investment analysts in Nigeria should embrace the use of Monte Carlo Simulation in their analysis so as to facilitate a more efficient investment decision making by the investors through the various probabilities of outcomes that could be derived from Monte Carlo simulation results.

\section{References}

Adair, A. (1996). European Valuation Practice : Theory and Technique. Oxford: Spon Press.

Amderee-Manesme. C., Baroni. M, Barthelemey. F and Dupuy. E (2011). Combining Monte Carlo Simulations and Options to manage Risk of Real Estate Portfolios Journal of Real Estate Literature, 37(3), 233-64

Babawale G.K. (2007). Risk Analysis in Property Investment using Monte Carlo Simulation technique. Journal of Land use and Development Studies,3(1).

Balogh, P., Golea, P., and Inceu, V. (2013). Profit Forecast Model Using Monte Carlo Simulation in Excel. Romanian Statistical Review, 61(12), 33-40.

Baroni, M, Barthelemy, F. and Mokrane, M. (2005). Physical Real Estate: A paris Repeat Sales Residential Index. Journal of Real Estate Literature, 2(13), 303-324.

Baroni, M, Barthelemy, F. and Mokrane, M. (2006). Monte Carlo Simulations versus DCF in Real Estate Portfolio Valuation. ESSEC, centre De Recherche JEL Classification code: C15, G12

Damodaran, A. (2002). Investment Valuation - Tools and Techniques for Determining the Value of Any Asset.

Dupuy, E. (2003). Real Estate options Risk Analysis of Cash Flows; Taking real estate Analysis forward, a working paper

Fetibegovic, A and Nilsson, A (2011). Real Estate Discounted Cash Flow, MSc Thesis NO 97, Department of Real Estate Management, KTH Royal Institute of Technology, Stockholm, Sweden.

French, N. and Gabrielli, L. (2004). The Uncertainty of Valuation. Journal of Property Investment and Finance, 23(6), 485-500

Hoesli, M., Jani, E. and Bender, A. (2006). Monte Carlo simulations for real estate valuation, Journal of Property Investment and Finance, 24 (2), 102-122.

Jayaraman, S . (2013). A Review of Monte Carlo. Florida State University

Keith, C.L. (2014). Beyond DCF Analysis in real estate financial modeling: Probabilistic Evaluation of real estate ventures. Msc project dissertation submitted to the Massachuset Institute of Technology 
Kelliher, C. F.; and Mahoney, L. S. (2000). Using Monte Carlo Simulation to Improve Long Term Investment Decisions. The Appraisal Journal, pp. 44-56.

Martin, R. (2010). A different take on inflation hedging from property. Property research reporting from Legal and General Property.

Ojo, B. (2006). Development appraisal practice and risk adjustment in commercial property development in Lagos metropolis. Journal of Land Use and Development Studies.

2(1),pp.1 12

Pyhrr, S.A (1973). A complete Simulation Model to Measure Risk in Real Estate Investment. Journal of America Real Estate and Urban Economic Association. 1 (1), pp. 48-78.

Suhonen, V. (2014). Using Monte Carlo Simulation to Support a Retail Real Estate Investment Decision. A Master's Degree thesis submitted to the Department of Real estate, planning and Geoinformatics, Aalto University

Udoekanem, N., Ighalo, J.I. and Nuhu M..B (2014). Determinants Of Property Rental Growth in Minna, Nigeria EUL Journal of Social Sciences (V:I) LAÜ Sosyal Bilimler Dergisi.

Wayne L. W, (2004), Microsoft Excel Data Analysis and Business Modeling, Microsoft Press 